\title{
VARIASI MORFOMETRIK PADA BEBERAPA LAMUN DI PERAIRAN SEMENANJUNG MINAHASA
}

(Morphometric Variation of the Different Seagrass in Minahasa Peninsula Waters)

\author{
Weby Frengky Sakey ${ }^{{ }^{\star}}$, Billy T. Wagey ${ }^{1}$, Grevo S. Gerung ${ }^{1}$
}

1. Program Studi Ilmu Kelautan, Fakultas Perikanan dan IImu Kelautan, Universitas Sam

Ratulangi, Manado

*e-mail : sakeyweby@gmail.com

Lamun (seagrass) atau disebut juga ilalang laut. Istilah lamun untuk seagrass, pertamatama diperkenalkan oleh Hutomo dimana merupakan satu-satunya kelompok tumbuhan hidup di perairan laut dangkal. Lamun tumbuh padat membentuk padang, sehingga dikenal sebagai padang lamun (seagrass beds). Penelitian pada ekosistem padang lamun dimana banyak terjadi kegiatan atau aktivitas pemanfaatan oleh manusia sangatlah terbatas. Oleh karena itu, penelitian ini perlu diadakan sehingga dapat dijadikan sebagai informasi awal bagi peneliti di perairan semenanjung Minahasa. Pengumpulan data dilaksanakan di Perairan Semenanjung Minahasa Sulawesi Utara, khususnya di desa Arakan dan desa Tongkeina. Pengambilan sampel dilakukan dengan menggunakan metode jelajah. Sampel yang telah diperoleh (30 individu per species), diidentifikasi, diukur dengan aplikasi image-J gambar dan diolah menggunakan aplikasi SPSS versi 20.Rata-rata ukuran empat spesies yang diidentifikasi, memiliki variasi dan perbedaan antara spesies yang satu dengan spesies yang lain. Untuk spesies Cymodocea serrulata dan Thalassia hemprichii yang tumbuh di Tongkeina berukuran lebih panjang dibanding yang tumbuh di Arakan. Sedangkan untuk spesies Halodule pinifolia, terlihat yang tumbuh di Arakan yang memiliki ukuran lebih panjang dari Halophila ovalis. Hasil pengukuran menggunakan Hobo Pendant loggers di Arakan : intensitas cahaya 130000-139000 lux dan temperatur $36-37{ }^{\circ} \mathrm{C}$. Di Tongkeina intensitas cahaya $230000-240000$ lux dan temperatur $31-32{ }^{\circ} \mathrm{C}$.Secara umum dapat disimpulkan bahwa ketiga spesies baik yang tumbuh di arakan maupun yang tumbuh di Tongkeina memiliki variasi morfometrik.

Kata kunci : Morfometrik, Image-J, Semenanjung Minahasa, Arakan, Tongkeina

Seagrass or also called sea weeds. The term for seagrass, first introduced by Hutomo which is the only group of plants live in shallow marine waters. Seagrass meadows grow solid form, so it is known as seagrass beds. Research in seagrass ecosystems where there have been activities or utilization by human activity is very limited. Therefore, this research needs to be conducted so that it can be used as initial information for researchers in the waters of the Minahasa peninsula.Data collection was carried out in the waters of North Sulawesi Minahasa Peninsula, particularly in the rural village of Arakan and Tongkeina. Sampling was done by using roaming. Samples were obtained ( 30 individuals per species ), identified, measured by image - $\mathrm{J}$ application image and processed using SPSS version 20 . The average size of the four species were identified, has variations and differences between the species with other species. For species Cymodocea serrulata and Thalassia hemprichii growing in Tongkeina is longer than that grown in Arakan. As for Halodule pinifolia species, seen growing in Arakan which has a longer size Halophila ovalis. The results of measurements using Hobo Pendant loggers in Arakan : $130000-139000$ lux light intensity and temperature of $36-37{ }^{\circ} \mathrm{C}$. In Tongkeina $230000-240000$ lux light intensity and temperature of $31-32^{\circ} \mathrm{C}$ In general it can be concluded that the three species that grow well in the procession as well as the growth in Tongkeina have morphometric variation.

Keywords : Morphometric, Image-J, Minahasa peninsula, Arakan, Tongkeina 


\section{PENDAHULUAN}

Lamun (seagrass) atau disebut juga ilalang laut. Istilah lamun untuk seagrass, pertama-tama diperkenalkan oleh Hutomo kepada para ilmuwan dan masyarakat umum pada era tahun 1980-an dalam disertasinya yang berjudul "Telaah Ekologik Komunitas Ikan pada Padang Lamun di Teluk Banten" (Hutomo, 1985), merupakan satu-satunya kelompok tumbuhan hidup di perairan laut dangkal.

Lamun tumbuh padat membentuk padang, sehingga dikenal sebagai padang lamun (seagrass beds). Lamun dapat tumbuh membentuk padang lamun dengan kepadatan mencapai 4.000 tumbuhan per $\mathrm{m}^{2}$ dan mempunyai biomassa tetap sebesar 2 $\mathrm{kg} / \mathrm{m}^{2}$. Padang lamun dapat membentuk vegetasi tunggal, tersusun atas satu jenis lamun yang tumbuh membentuk padang lebat, sedangkan vegetasi campuran terdiri dari 2-12 jenis lamun yang tumbuh bersamasama pada satu substrat. Spesies lamun yang biasanya tumbuh dengan vegetasi tunggal adalah Thalassia hemprichii, Enhalus acoroides, Halophila ovalis, Halodule uninervis, Cymodocea serrulata, dan Thalassodendrom ciliatum. Sedangkan yang tumbuh dengan vegetasi campuran adalah Cymodocea rotundata, Halodule pinifolia, dan Syringodium isoetifolium.

Penelitian pada ekosistem padang lamun dimana banyak terjadi kegiatan atau aktivitas pemanfaatan oleh manusia sangatlah terbatas. Dengan adanya penelitian ini, diharapkan dapat memperoleh gambaran mengenai morfologi dan ekosistem padang lamun di daerah yang banyak kegiatan atau aktivitas yang dilakukan oleh manusia, sehingga dapat dijadikan sebagai informasi awal bagi peneliti di perairan semenanjung Minahasa. Didasarkan pada pentingnya keberadaan ekositem lamun di perairan pantai maka pengetahuan mengenai morfologi lamun perlu dipelajari baik untuk kepentingan ilmiah maupun kepentingan pengetahuan lamun itu sendiri, juga sebagai bahan informasi dengan cara teknik pengukuran morfologi lamun dengan menggunakan image-J.

Lamun merupakan tumbuhan berbunga (Angiospermae) yang memiliki kemampuan beradaptasi secara penuh di perairan yang memiliki fluktuasi salinitas tinggi, hidup terbenam di dalam air dan memiliki rhizoma, daun, dan akar sejati.

Berbeda dengan rumput laut (seaweed), lamun memiliki akar, batang dan daun sejati sehingga dikategorikan sebagai tumbuhan tingkat tinggi. Lamun juga berbunga, berbuah dan menghasilkan biji (Green \& Short, 2003; Romimohtarto \& Juwana, 2007). Selain itu lamun dikenal sebagai tumbuhan berrumah dua, yaitu dalam satu tumbuhan hanya ada bunga jantan saja atau bunga betina saja (Nontji, 2002), Waycott (2004), Mellors and McKenzie (2009) membedakan lamun berdasarkan bentuk morfologinya yakni dengan melihat bentuk akar, rhizoma, batang dan daun.

$H$. pinifolia hidup di zona sublittoral, biasanya tumbuh di dasar berpasir atau berlumpur. Observasi menunjukkan bahwa spesies ini hidup di lingkungan energi tinggi maupun rendah, namun sebagian besar berada di teluk yang terlindung dan di wilayah yang tergenang air saat surut terendah. Spesies ini merupakan spesies pioner yang dominan dalam lingkungan perairan yang mengalami gangguan atau di lingkungan yang tidak menguntungkan bagi spesies lamun lainnya. Lingkungan yang tidak menguntungkan ini, termasuk daerahdaerah yang mengalami fluktuasi musiman salinitas, perpindahan substrat pasir dan kerusakan mekanik.

Pada mulanya, Miki memberi nama $H$. pinifolia pada tahun 1932 sebagai Diplanthera pinifolia dan kemudian dinamakan $H$. pinifolia (Den Hartog, 1964). Spesies ini secara luas 
terdistribusi ke seluruh wilayah Samudera Pasifik bagian barat dan Samudera Hindia bagian timur. Spesies ini tercatat ditemukan di Jepang, Taiwan, Filipina, Malaysia, Indonesia, Vietnam, Cina, Kepulauan Mariana Utara, Kepulauan Fuji, India dan di seluruh Australia. Diduga bahwa $H$. uninervis dan Halodule beaudettei berasal dari $H$. pinifolia. Namun penelitian yang dilakukan membuktikan bahwa spesies-spesies $H$. uninervis dan $H$. pinifolia adalah dua spesies yang berbeda (Wagey, 2011).

Spesies C. serrulata, yang diterjemahkan ke bahasa Latin "agak terlihat bergigi", menggambarkan sifat bergerigi helai daun lamun ini. Awalnya digambarkan sebagai Caulinia serrulata oleh R. Brown pada tahun 1810, kemudian diganti oleh Acherson dan Magnus tahun 1870. Saat ini, tercatat dengan nama Cymodocea. . Secara morfologi, $C$. serrulata serupa dengan C. rotundata, Thalassia hemprichii, dan Thalassodendron ciliatum sehingga sering membingungkan.

Thalassia hemprichii adalah lamun yang sangat umum dan penyebarannya luas di kawasan IndoPasifik. Tumbuhan ini adalah jenis lamun yang dominan dan merupakan spesies yang paling luas distribusinya di Indonesia. Rentang distribusi untuk T. hemprichii meliputi pantai timur Afrika, dari selatan Laut Merah ke Mozambik, Madagaskar, Seychelles, Maladewa dan Sri Lanka. Lamun ini juga ditemukan di selatan Jepang ke Taiwan, Cina, Filipina, Australia, Kaledonia Baru dan Kepulauan Marshall. Spesies T. hemprichii ini biasanya ditemukan di zona sublittoral di kedalaman sampai 5 meter. Lamun ini berada dalam kepadatan tinggi yang membentuk padang lamun monospesifik dan merupakan jenis lamun yang dominan pada rataan karang mati dengan sedimen yang terdiri dari pasir karang dan pecahan karang. Spesies ini juga telah diamati tumbuh pada substrat pasir berlumpur dan lumpur lunak, serta lumpur tertutup karang.

Tumbuhan $H$. ovalis adalah spesies dari genus Halophila dengan nama umum, yaitu "gulma dugong". Spesies ini adalah tanaman herbal kecil yang hidup didasar laut. Spesies ini tumbuh di sekitar daerah terumbu karang, muara sungai, pulau-pulau, di antara wilayah pasang surut, di atas pasir lunak atau substrat berlumpur. Secara umum, daun bulat telur, muncul dari batang yang berasal dari rhizoma di bawah pasir. Panjang akar mencapai hingga $800 \mathrm{~mm}$ dan ditutupi rambut akar halus. Spesies ini sering ditemukan di padang lamun yang didominasi pasir atau kumpulan kecil pasir lainnya dari dasar laut.

\section{METODE PENELITIAN}

Pengumpulan data dilaksanakan di Perairan Semenanjung Minahasa Sulawesi Utara, khususnya di desa Arakan dan desa Tongkeina. Desa Arakan terletak dalam posisi geografis $1^{0} 22^{\prime} 38,52$ 'N - $124^{\circ} 33^{\prime} 17,74$ "E. Sedangkan desa Tongkeina terletak dalam posisi geografis antara $1^{0} 34^{\prime} 12,55^{\prime \prime} \mathrm{N}-124^{0} 48^{\prime} 29,24^{\prime \prime} \mathrm{E}$.

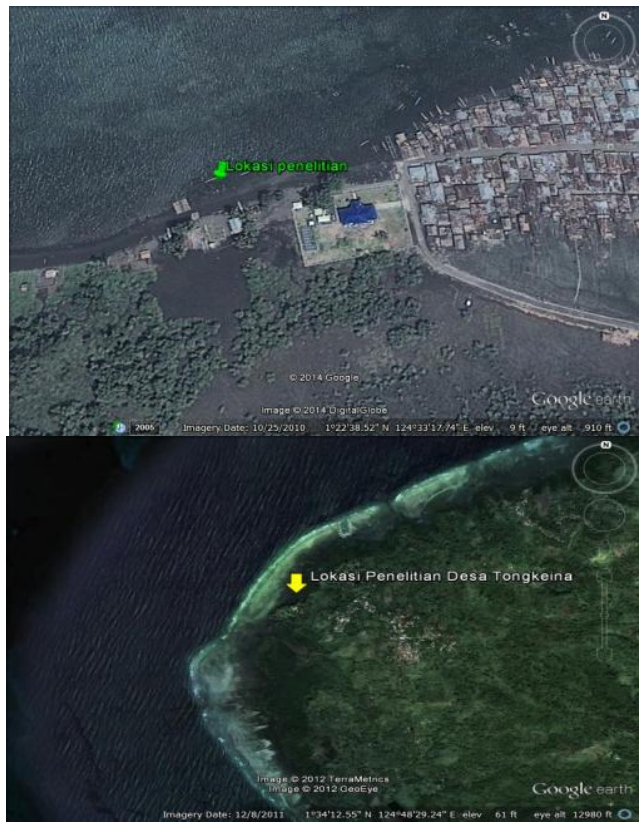

Gambar 1. Lokasi penelitian 
Pengambilan sampel dilakukan dengan menggunakan metode jelajah, sampel yang telah diperoleh 4 spesies (30 individu per species) kemudian dibawa ke Laboratorium untuk diidentifikasi lebih lanjut. Selanjutnya, dilakukan pengambilan gambar sampel menggunakan kamera, kemudian dengan aplikasi image-J gambar diukur setelah itu data hasil pengukuran diolah menggunakan aplikasi SPSS versi 20. Informasi mengenai temperatur dan intensitas cahaya diperoleh dengan menggunakan alat Hobo Pendant Logger. Alat ini diletakkan pada dua titik di lokasi Penelitian, pertama di perairan yang dekat pantai dan kedua di perairan yang dekat coral reef. Adapun alat ini diletakkan kurang lebih selama satu hari, kemudian diambil untuk ditransfer data yang telah terekam.

\section{HASIL DAN PEMBAHASAN}

\section{a. Cymodocea serrulata}

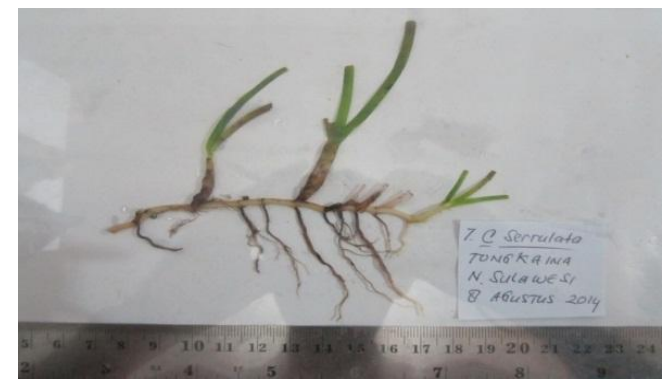

Gambar 2. Cymodocea serrulata

Memiliki daun yang berbentuk seperti pita yang lurus atau sedikit melengkung. Setiap tegakkan terdiri dari 2-3 helai daun. Dengan panjang daun 5,9-14,1 cm dan lebar 0,2-0,8 $\mathrm{cm}$. Mempunyai ukuran batang yang pendek dan akar yang bercabang menempel pada rhizoma. Secara umum terlihat rhizoma berwarna kuning sampai kecoklatan.

\section{b. Halodule pinifolia}

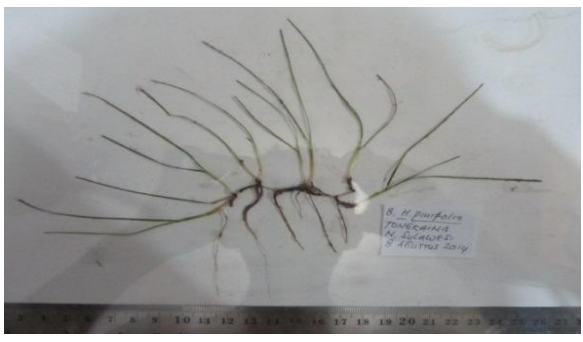

Gambar 3. Halodule pinifolia

Spesies ini memiliki daun yang sangat panjang sekitar $6,9-15,2 \mathrm{~cm}$ dan sangat sempit dengan lebar sekitar 0,1-0,2 cm. Dan setiap tegakan terdapat 1-2 helai daun. Ukuran batang yang pendek dengan akar yang tumbuh dari rhizoma yang memiliki warna coklat kehitaman.

c. Thalassia hemprichii

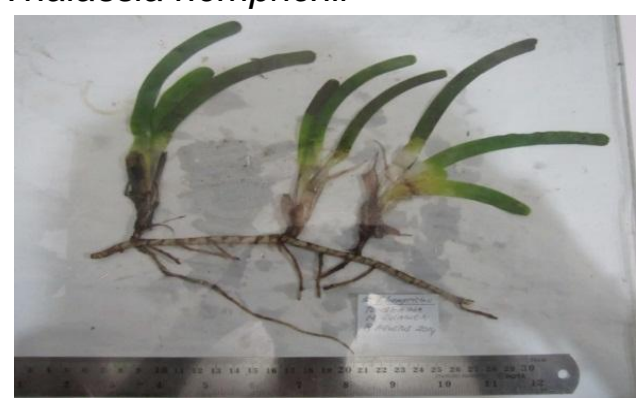

Gambar 4. Thalassia hemprichii

Sama halnya dengan Cymodocium serrulata, daun spesies ini berbentuk seperti pita dan tumbuh agak melengkung berbentuk seperti sabit yang tebal. Setiap tegakkan rata-rata memiliki 3 helai daun. Mempunyai batang dengan pelepah daun yang menyelimuti dan akar serta rhizoma berbentuk seperti saluran yang berbuku-buku.

d. Halophila ovalis

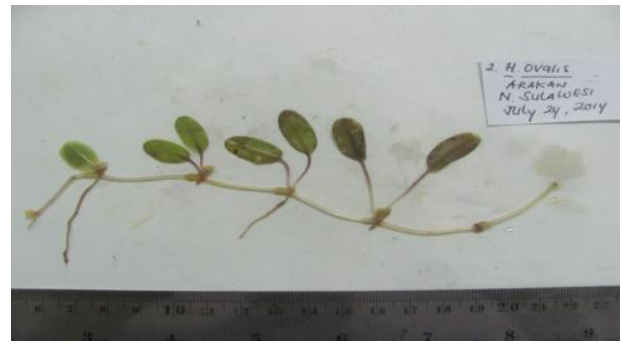

Gambar 5. Halophila ovalis 
Spesies ini hidup pada substrat berlumpur, memiliki daun yang berbentuk bulat telur (oval) berpasangan, ujung daun agak bulat dan akar tidak berambut. Serta memiliki rhizoma yang mudah patah.

\section{e. Pengukuran Morfologi}

Tabel 1. Hasil pengukuran lamun di Arakan

\begin{tabular}{|l|l|l|l|l|l|}
\hline Spesies & \multicolumn{1}{c|}{ a } & b & \multicolumn{1}{c|}{ c } & d & e \\
\hline C. & $6-$ & 0,2 & 2,6 & $4,3-$ & 2,2 \\
serrulata & 9,6 & - & - & 11, & - \\
& & 0,5 & 6,6 & 8 & 6,9 \\
\hline$H$. & 10,8 & 0,1 & 3,3 & $6,7-$ & 3,2 \\
pinifolia & -15 & - & - & 13, & - \\
& & 0,2 & 7,8 & 4 & 6,3 \\
\hline $\begin{array}{l}\text { h. } \\
\text { hemprich }\end{array}$ & $5,7-$ & 0,4 & $3-$ & $2,8-$ & 3,7 \\
ii & 12,1 & -1 & 6,5 & 12, & - \\
\hline H. ovalis & $1,7-$ & 0,9 & $1-$ & $1,7-$ & 1,6 \\
& 4 & - & 4,2 & 5,9 & - \\
& & 1,9 & & & 4,3 \\
\hline
\end{tabular}

Tabel 2. Hasil pengukuran lamun di Tongkeina

\begin{tabular}{|l|l|l|l|l|l|}
\hline Spesies & \multicolumn{1}{|c|}{$\mathrm{a}$} & \multicolumn{1}{c|}{$\mathrm{b}$} & $\mathrm{c}$ & \multicolumn{1}{c|}{$\mathrm{d}$} & \multicolumn{1}{c|}{ 伎 } \\
\hline C. & $5,9-$ & 0,3 & 3,2 & $4,3-$ & $2,2-$ \\
serrulata & 14, & - & - & 14, & 10, \\
& 1 & 0,8 & 7,7 & 1 & 9 \\
\hline H. & $6,9-$ & 0,1 & 2,8 & $4,5-$ & $2,3-$ \\
pinifolia & 15, & & - & 11, & 4,7 \\
& 2 & & 4,5 & 8 & \\
\hline T. & $7,7-$ & 0,6 & 3,9 & $3,1-$ & $4-$ \\
hemprich & 16, & - & - & 14, & 11, \\
ii & 8 & 1,6 & 9,3 & 8 & 9 \\
\hline H. ovalis & $1,5-$ & 0,7 & 1,1 & $2,2-$ & $1,3-$ \\
& 3,2 & - & - & 5,9 & 4,1 \\
& & 1,5 & 3,2 & & \\
\hline
\end{tabular}

$\mathrm{a}=$ panjang daun $(\mathrm{cm})$

$\mathrm{b}=$ lebar daun $(\mathrm{cm})$

$\mathrm{c}=$ panjang batang $(\mathrm{cm})$

$\mathrm{d}=$ panjang akar $(\mathrm{cm})$

$\mathrm{e}=$ panjang rhizoma $(\mathrm{cm})$

Pada hasil yang diperoleh, terlihat bahwa spesies Cymodocea serrulata di desa Arakan lebih kecil dibandingkan Cymodocea serrulata di desa Tongkeina. Hal ini disebabkan aktivitas masyarakat desa Arakan dilakukan dipinggir pantai, kemudian pembuangan limbah ke laut yang juga menyebabkan air laut keruh dan mempengaruhi pertumbuhan spesies ini akibat proses fotosintesis yang tidak efektif. Serta substrat lunak yang membuat spesies tidak memiliki tahanan ketika arus datang, sehingga kehidupan spesies ini tidak stabil dan mudah terbawa arus. Sedangkan spesies Cymodocea serrulata di desa Tongkeina lebih besar karena proses fotosintesis berjalan efektif dimana kondisi air jernih dan bersih. Kemudian ditunjang oleh substrat yang berpasir sehingga spesies ini tahan terhadap arus.

Berdasarkan hasil penelitian, ukuran spesies Halodule pinifolia yang tumbuh di Arakan lebih besar daripada di Tongkeina. Walaupun kondisi lingkungan desa Arakan yang tidak begitu mendukung pertumbuhan spesies ini, akan tetapi karena kemampuan spesies ini yang merupakan spesies pioner yang dominan dalam lingkungan perairan yang mengalami gangguan dan lingkungan yang tidak mendukung bagi spesies lainnya, maka spesies dapat bertumbuh dan berkembang dengan baik.

Pada kedua lokasi penelitian terdapat perbedaan ukuran morfologi spesies Thalassia hemprichii, dimana spesies yang tumbuh di Arakan lebih kecil dibanding yang tumbuh di Tongkeina. Melihat keadaan lingkungan dikedua lokasi ini, bahwa lingkungan di desa Tongkeina lebih menunjang pertumbuhan dan perkembangan spesies Thalassia hemprichii, dapat dilihat dari ukuran daun, batang, akar dan rhizoma yang lebih panjang.

Spesies Halophila ovalis di kedua lokasi penelitian terdapat perbedaan hanya pada lebar daun, sedangkan panjang daun, batang akar dan rhizoma tidak memiliki perbedaan. Secara umum, Halophila ovalis hidup pada kondisi sedimen lunak dimana 
cahaya selalu ditutupi lumpur. Di Arakan dengan kondisi substrat yang berlumpur menyebabkan spesies ini memiliki ukuran daun yang lebih lebar, sebaliknya di Tongkeina dengan substrat yang berpasir sehingga daun spesies ini lebih kecil.

f. Temperatur dan intensitas cahaya

Tabel 3. Fluktuasi temperatur dan intensitas cahaya

\begin{tabular}{|c|c|c|}
\hline Lokasi & Temperatur & $\begin{array}{c}\text { Intensitas } \\
\text { cahaya }\end{array}$ \\
\hline Arakan & $36-37^{\circ} \mathrm{C}$ & $\begin{array}{c}130000- \\
139000 \text { lux }\end{array}$ \\
\hline Tongkeina & $31-32{ }^{\circ} \mathrm{C}$ & $\begin{array}{c}230000- \\
240000 \text { lux }\end{array}$ \\
\hline
\end{tabular}

Berdasarkan pengukuran yang dilakukan menggunakan Hobo pendant loggers, hasilnya adalah intensitas cahaya 130000-139000 lux dan temperatur $36-37^{\circ} \mathrm{C}$. Untuk intensitas cahaya, hasil ini lebih rendah dibandingkan hasil di desa Tongkeina. Hal ini berkaitan dengan aktivitas masyarakat yang dilakukan didaerah pinggiran pantai sehingga penetrasi cahaya rendah. Menurut Nybakken (1992) bahwa temperatur memiliki pengaruh yang sangat besar bagi lamun karena akan mempengaruhi fotosintesis maupun pertumbuhan. Kisaran temperatur yang baik bagi pertumbuhan lamun yakni $28-30^{\circ} \mathrm{C}$ dan untuk proses fotosintesis temperatur optimumnya $35^{\circ} \mathrm{C}$. Dibandingkan hasil di Arakan, terlihat bahwa di Arakan temperatur tidak mendukung dalam proses pertumbuhan dan fotosintesis (Wagey, 2012).

Hasil yang diperoleh di perairan Tongkeina berdasarkan pengukuran yang dilakukan menggunaka Hobo pendant loggers adalah intensitas cahaya 230000-240000 lux, hasil ini lebih tinggi dibandingkan hasil di Arakan sehingga dapat disimpulkan penetrasi cahaya lebih ringgi dan temperatur $31-32^{\circ} \mathrm{C}$ menunjukkan temperatur yang baik bagi pertumbuhan lamun, sehingga morfologi lamun yang tumbuh di Tongkeina lebih panjang akibat kondisi lingkungan yang mendukung (Wagey, 2013).

\section{KESIMPULAN}

Berdasarkan hasil dan pembahasan yang dikemukakan dengan jumlah spesies dan jumlah individu yang ditemukan di dua lokasi penelitian yaitu desa Arakan dan desa Tongkeina, dapat ditarik kesimpulan bahwa :

1. Teridentifikasi bahwa jenis lamun yang terdapat di wilayah perairan Semenanjung Minahasa, khususnya di Desa Arakan dan Desa Tongkeina adalah $C$. serrulata, $H$. pinifolia, T.hemprichii, dan $H$. ovalis.

2. Dari keempat spesies yang teridentifikasi, terdapat perbedaan dan variasi ukuran morfologi pada masing-masing spesies dikedua lokasi berbeda. Untuk spesies $C$. serrulata dan Thalassia hemprichii yang tumbuh di Tongkeina berukuran lebih panjang dibanding di Arakan. Sedangkan untuk spesies $H$. pinifolia dan $H$. ovalis, terlihat yang tumbuh di Arakan memiliki ukuran lebih panjang dibandingkan di Tongkeina.

3. Hasil pengukuran menggunakan Hobo pendant loggers di Arakan : intensitas cahaya 130000-139000 lux dan temperatur $36-37{ }^{\circ} \mathrm{C}$. Di Tongkeina intensitas cahaya 230000-240000 lux dan temperatur $31-32{ }^{\circ} \mathrm{C}$.

\section{DAFTAR PUSTAKA}

Den Hartog, C. 1964. An Approach to the Taxonomy of the Seagrass Genus Halodule (potamogetonaceae) Blumea. 12(2):289-312

Green, E.P., Short, F.T. 2003. World Atlas of Seagrasses. University of 
California Press. Erkeley Los Angeles London. p 298.

Hutomo. 1985. Telaah Ekologi Komunitas Ikan pada Padang Lamun di Teluk Banten. Fakultas Pasca Sarjana. IPB. Bogor. 271 hal.

Mellors, J., McKenzie, L. 2009. Seagrass Monitoring Guidelines for Torres Strait Communities. Seagrass - Watch $\mathrm{HQ}$. Townsville, Australia. p 60.

Nontji, A. 2002. Laut Nusantara Suatu Pendekatan Djambatan. Jakarta. 367 hal.

Romimohtarto, K., Juwana, S. 2007. Biologi Laut : IImu Pengetahuan tentang Biota Laut. Djambatan. Jakarta. 540 hal.

Wagey, B.T. 2011. Morphology and Genetic Charsacterization of Seagrass Genus Halodule in Central Visayas Philipines. Disertation. Siliman University.

Wagey, B.T. 2012. Common Garden of Seagrass Halodule Uninervis (Forsskal) Aschershon AND Halodule Pinifolia (MIKI) den Hartog.

http://ejurnal.unsrat.ac.id/index.ph p/jpkt/article/download/368/876.

Diakses tanggal 3 april 2015, pukul 11.30.

Wagey, B.T. 2013. Variation In Chlorphyll $a$ and $b$ the Seagrass Halodule In Central Visayas, Philippines. iamure.com/publication/index.php /ijec/article/view/748. Diakses tanggal 3 april 2015, pukul 11.45.

Waycott, M., McMahon, K., Mellors, J., Calladine, A., Kleine, D.. 2004. A Guide to : Tropical Seagrasses of the Indo-West Pacific. James
Cook University. Australia. p 72. 